\title{
Passage and digestibility of lucerne (Medicago sativa) hay in Japanese sika deer (Cervus nippon) and sheep under restricted feeding
}

\author{
BY K. KATOH, Y. KAJITA, M. ODASHIMA, M. OHTA AND Y. SASAKI \\ Department of Animal Physiology and Kawatabi University Farm, Faculty of Agriculture, \\ Tohoku University, Tsutsumidori Amamiyamachi, Sendai 981, Japan
}

(Received 1 October 1990 - Accepted 5 March 1991)

\begin{abstract}
The mean retention time (MRT) of stained hay through the whole digestive tract and its digestibility were measured in Japanese sika deer (Cervus nippon) and were compared with those in sheep when lucerne (Medicago sativa) hay was fed at 10,20 and $30 \mathrm{~g} / \mathrm{kg}$ body-weight. The recoveries in faeces of plastic particles with five specific gravities were also measured in deer. MRT for deer was significantly shorter than that for sheep at 10 and $20 \mathrm{~g} / \mathrm{kg}$ feeding levels. The digestibilities of dry matter, organic matter, and neutral-detergent fibre were significantly lower for deer than for sheep at 30,30 and $10 \mathrm{~g} / \mathrm{kg}$ feeding levels respectively. The recovery rates of plastic particles were increased, but the ruminated rates were decreased, with increasing specific gravity in deer. These results suggest that the lower digestibility of lucerne hay in Japanese deer may be due to a shorter MRT compared with sheep.
\end{abstract}

Food passage: Digestibility : Restricted feeding : Sika deer

Japanese sika deer (Cervus nippon), long hunted as a game animal, have recently been suggested as a candidate for domestication for the production of meat. They inhabit low hills where they eat a type of dwarf bamboo (Sasa nipponica) (Takatsuki, 1989). According to food habits and morphological signs of adaptation to digest fibre, sika deer have been classified in the intermediate-adaptable-feeder group of ruminants (Hofmann, 1985). However, the digestive functions of sika deer have not been compared with those of domesticated ruminant animals. Our purpose in the present study was to measure the mean retention time (MRT) and digestibility of lucerne (Medicago sativa) hay in sika deer and sheep at three feeding levels, and to measure the recovery rate of plastic particles of various specific gravities in sika deer. The results suggest that Japanese sika deer show a shorter passage time, and accordingly lower digestibility, than sheep.

EXPER I MENTA L

Experimental procedure

Two experiments were undertaken for 3 months from June to August 1988 at Tohoku University farm. In Expt 1, the MRT through the whole digestive tract and the digestibility of lucerne hay were determined in Japanese sika deer and sheep. In Expt 2, the recovery rates of excreted plastic particles of five different specific gravities (SG) were measured for deer.

Expt 1 was continued for 3 months using five castrated stags and five crossbred wethers. The mean body-weights on 31 May 1988 of deer and sheep were 47.6 and $46.6 \mathrm{~kg}$ respectively. Each animal was housed in a metabolism cage and fed on lucerne hay cubes 
at 09.00 hours every day. Three feeding levels, 10,20 and $30 \mathrm{~g} / \mathrm{kg}$ body-weight, were provided in ascending sequence, each level being continued for 1 month. On the 20 th day of each month, $40 \mathrm{~g}$ stained hay was fed to each animal at 09.00 hours after being mixed well with unstained hay. All faeces were collected and weighed for the next $10 \mathrm{~d}$ at $24 \mathrm{~h}$ intervals, and two faeces samples (each $100 \mathrm{~g} / \mathrm{kg}$ ) were stored below $-20^{\circ}$ to be used for determination of MRT and digestibility. The animals had free access to water.

In Expt 2, another three castrated stags were fed on lucerne hay cubes at $20 \mathrm{~g} / \mathrm{kg}$ bodyweight at 09.00 hours every day for 1 month. On the 20 th day they were dosed with 500 of each of five types of plastic particles differing in SG $(0.92,1.21,1.27,1.38$ and 1.87, indicated by their colour) suspended in about $100 \mathrm{ml}$ tap-water and introduced through a tube inserted into the reticulo-rumen as described previously (Katoh et al. 1988). Thereafter, they were allowed to eat lucerne-hay cubes containing stained hay ( $40 \mathrm{~g}$ per animal) and faeces were sampled as in Expt 1. The procedure for counting the number of plastic particles ruminated or non-ruminated has been described previously (Katoh et al. 1988). The ruminated particles were identified by teeth marks on the surface or deformation, or both. Plastic particles, when bitten and broken in several pieces, were collected and weighed in order to calculate the number of each type of particle.

The stained hay was made as described by Balch (1950). Brilliant green was used for staining. The number of stained hay particles in $3 \mathrm{~g}$ faeces was counted under an optical magnifier after washing the sample with tap-water on two layers of gauze, and expressed as the total number of particles excreted per $24 \mathrm{~h}$. MRT through the whole digestive tract was calculated by the method of Faichney (1975) from the area under an excretion curve of stained hay, the proportion of stained hay remaining to be excreted multiplied by the sampling period $(24 \mathrm{~h})$. The digestibilities of dry matter (DM), organic matter (OM), neutral-detergent fibre (NDF) and acid-detergent fibre (ADF) were determined by the standard procedure recommended by the National Institute of Animal Industry, Japan (Abe, 1988) after mixing all the faecal samples collected for $10 \mathrm{~d}$ for each animal in Expt 1. Lucerne hay offered to animals contained $873 \mathrm{~g} \mathrm{DM} / \mathrm{kg}$ hay, and $(\mathrm{g} / \mathrm{kg} \mathrm{DM}) 105 \mathrm{ash}$, 442 NDF and 358 ADF.

\section{Statistical analysis}

Results are given as means with their standard errors. In Expt 1, Student's $t$ test was employed to compare the mean values of MRT and feed digestibility for deer and sheep within each feeding level. In Expt 2, Spearman's rank correlation test was used to examine the correlation between the proportion recovered and specific gravities for total or ruminated plastic particles in deer (Zar, 1984). The difference was considered to be significant with $P<0.05$.

\section{RESULTS}

Expt 1

All the hay offered was eaten by animals of both species at all feeding levels. The mean body-weight fell by 8.9 and $11.2 \mathrm{~kg}$ after 1 month feeding at the $10 \mathrm{~g} / \mathrm{kg}$ body-weight level (30 June), but subsequently increased by 4.4 and $3.6 \mathrm{~kg}$ in deer and sheep respectively by 30 August.

Fig. 1 shows the daily and cumulative excretion rates of stained hay particles recovered from faeces collected for $7 \mathrm{~d}$ following a single feeding of stained hay. The maximum daily excretion rate was recorded on day 2 at each feeding level for deer, while that for sheep was recorded on day 3 except with the $30 \mathrm{~g} / \mathrm{kg}$ body-weight feeding level where it was day 2 . The maximum recorded values for deer were 46.4 (SEM 5.42), 42.1 (SEM 2.45) and 51.5 (SEM 4.25$) \%$, while those for sheep were 36.6 (SEM 4.38 ), 35.8 (SEM 1.43 ) and 41.2 (SEM 4.96) \% 
(a)

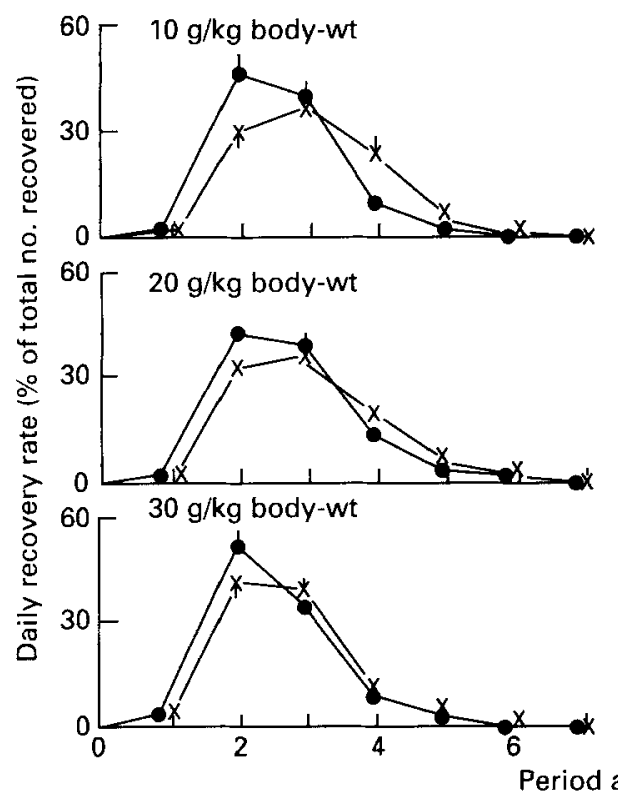

(b)

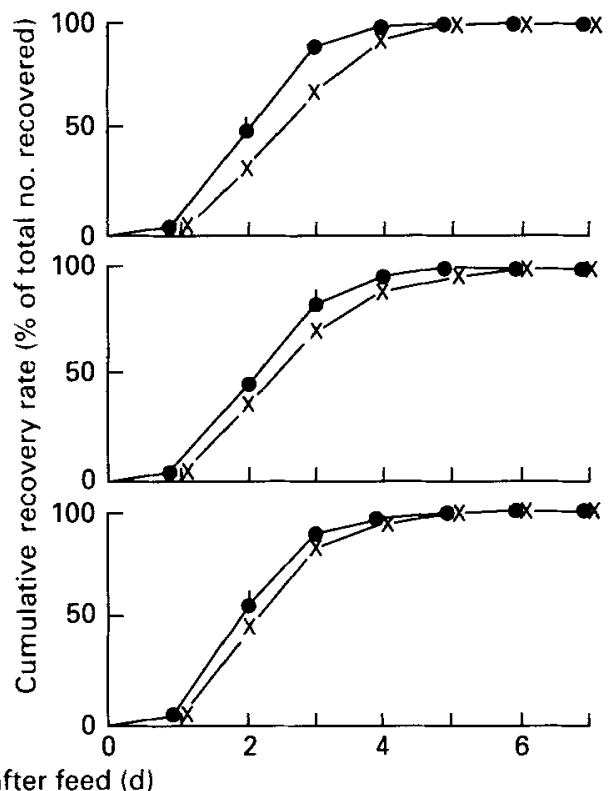

Fig. 1. (a) Daily and $(b)$ cumulative recovery rates (\% of total number recovered) of stained lucerne (Medicago sativa) hay particles excreted in the faeces of $(O)$ sika deer (Cervus nippon; $n$ ) and $(X)$ sheep $(n 5)$ during $7 \mathrm{~d}$ following a single feed ( $40 \mathrm{~g}$ stained hay per animal). Points are means with their standard errors represented by vertical bars. For details of procedures, see pp. $399-400$.

Table 1. Mean retention time (MRT; $h$ ) of stained lucerne (Medicago sativa) hay through the whole digestive tract at three feeding levels in sika deer (Cervus nippon; $\mathrm{n} 5$ ) and sheep (n 5) $\dagger$

(Mean values with their standard errors)

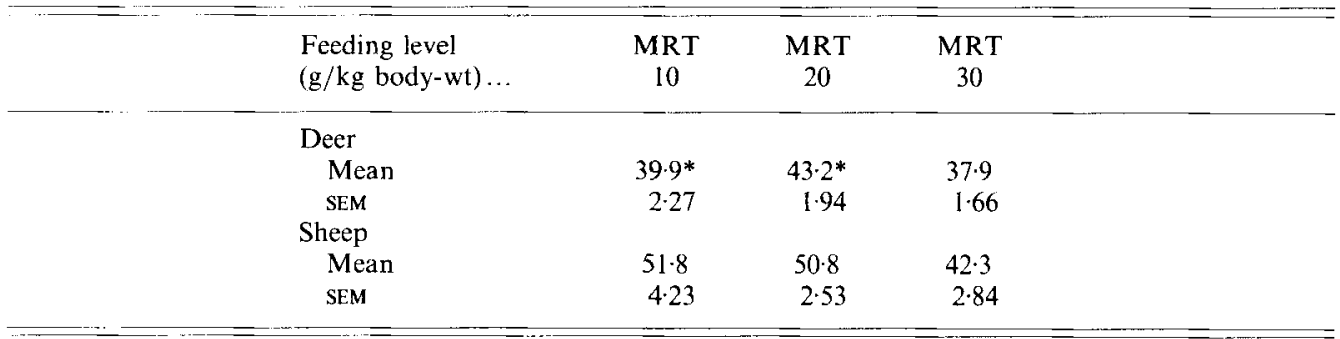

Mean values for deer and sheep at the 10 and $20 \mathrm{~g} / \mathrm{kg}$ body-wt feeding levels were significantly different $(t$ test $)$ : * $P<0.05$ )

$\dagger$ For details of procedures, see pp. $399-400$.

at the 10,20 and $30 \mathrm{~g} / \mathrm{kg}$ body-weight feeding levels respectively. The daily recovery rate of stained hay from day 8 to day 10 was less than 0.1 and $0.6 \%$ in deer and sheep respectively. The cumulative curves show a rapid increase in excretion of stained hay in deer and sheep from day 1 to day 4 following a stained hay feeding.

Table 1 shows MRT values calculated from the cumulative excretion rates of stained hay particles recovered from faeces. Statistical analysis ( $t$-test) showed that MRT values were significantly shorter for deer than those for sheep at 10 and $20 \mathrm{~g} / \mathrm{kg}$ body-weight feeding levels. 
Table 2. The digestibility of dry matter $(D M)$, organic matter $(O M)$, neutral-detergent fibre $(N D F)$ and acid-detergent fibre $(A D F)$ of lucerne (Medicago sativa) hay in sika deer (Cervus nippon; $\mathrm{n}$ 5) and sheep (n 5$) \dagger$

(Mean values with their standard errors)

\begin{tabular}{|c|c|c|c|c|c|c|}
\hline \multirow{2}{*}{$\begin{array}{l}\text { Feeding level } \\
(\mathrm{g} / \mathrm{kg} \text { body-wt }) \ldots\end{array}$} & \multicolumn{2}{|c|}{10} & \multicolumn{2}{|c|}{20} & \multicolumn{2}{|c|}{30} \\
\hline & Mean & SEM & Mean & SEM & Mean & SEM \\
\hline \multicolumn{7}{|l|}{ DM } \\
\hline Deer & 0.596 & 0.0054 & 0.600 & 0.0073 & $0.593^{*}$ & 0.0042 \\
\hline Sheep & $0-607$ & 0.0092 & 0.602 & 0.0019 & 0.614 & 0.0065 \\
\hline \multicolumn{7}{|l|}{$\mathrm{OM}$} \\
\hline Deer & $0 \cdot 603$ & 0.0052 & 0.607 & 0.0074 & $0.599 * *$ & 0.0041 \\
\hline Sheep & 0.622 & 0.0088 & 0.614 & 0.0022 & 0.626 & 0.0065 \\
\hline \multicolumn{7}{|l|}{ NDF } \\
\hline Deer & $0.478^{*}$ & 0.0094 & 0.502 & 0.0133 & 0.491 & 0.0058 \\
\hline Sheep & 0.528 & 0.0155 & 0.543 & 0.0162 & 0.539 & 0.0207 \\
\hline \multicolumn{7}{|l|}{$\mathrm{ADF}$} \\
\hline Deer & $0 \cdot 464$ & 0.0158 & 0.473 & 0.0079 & $0 \cdot 452$ & 0.0060 \\
\hline Sheep & 0.475 & $0 \cdot 0087$ & 0.495 & $0-0188$ & 0.487 & 0.0177 \\
\hline
\end{tabular}

Mean values for the digestibility of each dietary component within each feeding level for deer and sheep were significantly different: ( $t$ test) ${ }^{*} P<0 \cdot 05,{ }^{* *} P<0 \cdot 01$.

$\dagger$ For details of procedures, see pp. 399400 .

(a)

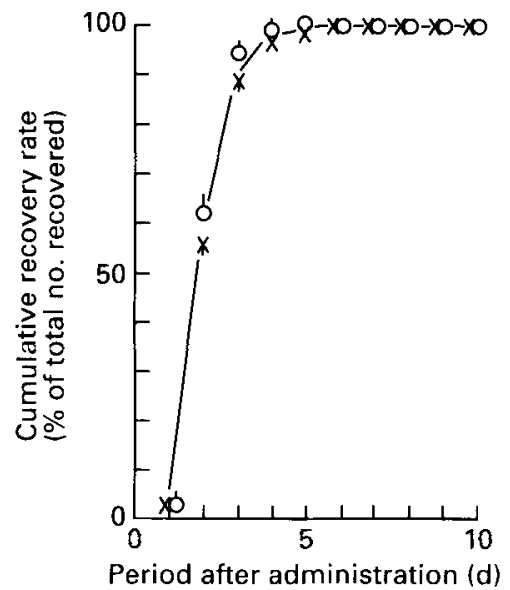

(b)

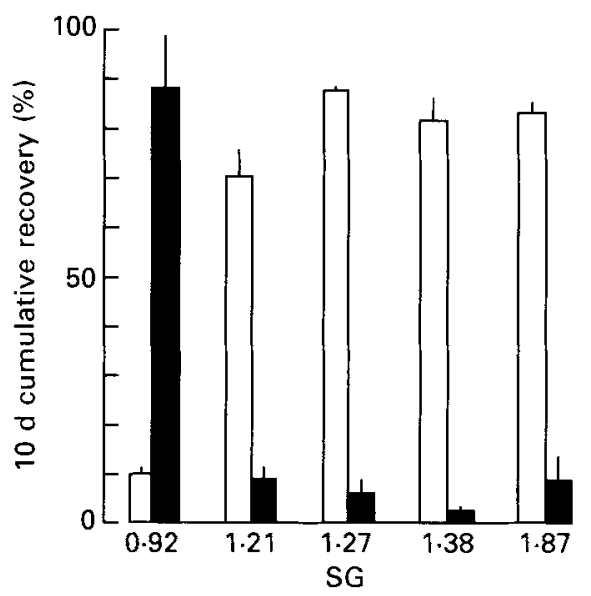

Fig. 2. (a) The cumulative recovery rates ( $\%$ of total number recovered) of indigestible plastic particles of specific gravity (SG) $1.87(X)$ and stained particles $(O)$ excreted in the faeces of sika deer (Cervus nippon) during $10 \mathrm{~d}$ following a single dose. (b) The recovery rates of plastic particles of a range of SG in deer up to day 10 after a single dose administered into the reticulo-rumen. ( $\square$ ), The total particles excreted (\% of number injected): ( $\square$ ), the number ruminated ( $\%$ of total number recovered). Values are means with their standard errors represented by vertical bars $(n 3)$. For details of procedures, see pp. 399-400.

Table 2 shows digestibilities of DM, OM, NDF and ADF in deer and sheep. The digestibility of each constituent for deer showed a tendency to be lower than that for sheep. The digestibility of DM, OM and NDF was significantly lower for deer than for sheep at 30,30 and $10 \mathrm{~g} / \mathrm{kg}$ body-weight feeding levels. 
Expt 2

Fig. 2(a) shows the cumulative recoveries of plastic particles with SG 1.87 and of stained hay particles in deer. The two excretion curves coincided closely. Fig. $2(b)$ shows the recovery rates after $10 \mathrm{~d}$ of whole plus ruminated (total) and of ruminated plastic particles with five different $S G$ in deer. The recovery rate of total excreted plastic particles was significantly $(P<0 \cdot 01)$ increased $(r 0.6898)$, but the recovery rate of ruminated particles was significantly $(P<0.05)$ decreased $(r-0.6283)$, with an increasing SG. The correlations between percentage recovery and $\mathrm{SG}$ for total or ruminated plastic particles were significant (by Spearman's rank correlation test; $P<0.01$ and $P<0.05$ respectively). The particles with SG 0.92 had the lowest recovery rate of total particles $(9.8$ (SEM 1.30$) \%$ ) but the highest recovery rate of ruminated particles $(87 \cdot 8$ (SEM 10.17) \%).

\section{DISCUSSION}

The present results indicate that MRT was shorter in Japanese sika deer than in sheep (Table 1) when lucerne hay was fed at 10 and $20 \mathrm{~g} / \mathrm{kg}$ body-weight. The shorter MRT found in deer seems to explain the decreased digestibility of DM, OM and NDF seen in this species. Kay \& Goodall (1976) reported that red deer (Cervus elaphus) showed lower digestibility and shorter MRT than sheep, and that MRT showed a tendency to decline with increasing DM intake when roughages were fed at four different levels of intake. Milne et al. (1978) measured MRT and digestibility in both these species when various kinds of diets were fed ad lib. at different times of the year, and they also found that MRT was shorter in red deer than in sheep. They reported that the MRT of the particulate-phase marker $\left[{ }^{103} \mathrm{Ru}\right]$ phenanthroline for deer and sheep when fed Agrostis-Festuca in April was 32.5 and $53.2 \mathrm{~h}$ respectively. Our results closely agree with these reported findings.

The recovery rate of total plastic particles was significantly increased, but the recovery rate of ruminated particles was significantly decreased with increasing SG in Japanese sika deer. In previous studies in which passage of indigestible plastic particles was measured, it was suggested that the recovery rate of total excreted particles depended critically on SG as well as on particle size in sheep (Katoh et al. 1988; Lechner-Doll \& Kaske, 1991), goats (Katoh et al. 1988) and cattle (desBordes \& Welch, 1984). For chromium-mordanted lucerne hay, the passage time was shown to be directly related to $S G$ over a range of $1 \cdot 12-1 \cdot 70$ (Ehle, 1984). The SG 0.92 particle was reported by Katoh et al. (1988) to stay in the reticulo-rumen of sheep and goats for longer than particles of heavier SG.

It is known that the length of the particles passing out of the reticulo-rumen is less than 1-2 $\mathrm{mm}$ in sheep and cattle (Poppi et al. 1980; Ulyatt et al. 1986). The plastic particles used for deer in the present experiment were $4 \mathrm{~mm}$ in length and $2 \mathrm{~mm}$ in diameter. Considering the size of plastic particles together with the fact that the recovery rate of plastic particles with SG 1.87 was similar to that of stained hay in the deer (Fig. 2(a)), it is suggested that the critical sizes of particles may increase with increasing SG in Japanese sika deer. This is in qualitative agreement with previous findings for sheep and goats (Katoh et al. 1988; Lechner-Doll \& Kaske, 1991).

The comparison of the $10 \mathrm{~d}$ cumulative recovery rates of total excreted particles in deer (Fig. 2(b)) with those reported previously for sheep and goats (Katoh et al. 1988) suggests that the particles with SG 1.21 and 1.27 would pass out of the reticulo-rumen more easily in deer than in sheep and goats. It is known that sika deer preferentially browse and eat broad-leaved plants more than grass, as do white-tailed deer (Odocoileus virginianus) (Henke et al. 1988), which have shorter MRT than goats and sheep (Kay, 1987). Following the recent classification of ruminants on the basis of their diet and the morphophysiological aspects of the alimentary tract (Hofmann, 1985), Cervidae include almost all groups of 
ruminant feeding types (concentrate selectors, intermediate and roughage eaters) except non-selective grazers of the roughage-eater type. However, detailed mechanisms for the shorter MRT in deer are not yet known, although it is reported that MRT in the stomach of deer is $60 \%$ of the total MRT (Milne et al. 1978) and that forestomach motility patterns in wapiti (Cervus canadensis) did not seem to differ substantially from those in cattle (Kay, 1987).

Japanese sika deer are characterized as adaptable animals and preferentially eat a dwarf bamboo as previously reported (Takatsuki, 1989). Although there is no information available on the utilization of Sasa nipponica in Japanese sika deer, it would be worth measuring MRT and the digestibility of this plant in future, since it is known that food digestibility is dependent on the type of forages: e.g. it was found that pelleted dried grass was digested better in sheep than in deer, but for heather (Calluna vulgaris) and meadow hay, Alopecurus pratensis, the reverse was true (Milne et al. 1978; Fennessy et al. 1980). It would be of interest, also, to know the effects of ad lib. feeding and seasonality on MRT and digestibility in Japanese sika deer, because the present experiments were carried out only in the summer season at restricted feeding levels, and it is known in red deer that appetite as well as breeding cycles are influenced by day-length (Kay, 1985).

The authors gratefully acknowledge Dr R. N. B. Kay for his criticism and help in preparing this manuscript, and thank Drs S. Oda and S. R. Lee and Messrs K. T. Nam, N. Matsunaga and $\mathrm{H}$. Senge for their help in the analysis of feed digestibility. This work was in part supported by a Grant-in-Aid for Scientific Research from the Japanese Education Ministry (no. 02660268) and the Ito Foundation.

\section{REFERENCES}

Abe, A. (1988). Feed analyses based on the carbohydrates and its application to the nutrition value of feed. In Memoirs of the National Institute of Animal Industry No. 2. Tsukuba, Japan: National Institute of Animal Industry.

Balch, C. C. (1950). Factors affecting the utilization of food by dairy cows. 1. The rate of passage of food through the digestive tract. British Journal of Nutrition 4, 361-388.

desBordes, C. K. \& Welch, J. G. (1984). Influence of specific gravity on rumination and passage of indigestible particles. Journal of Animal Science 59, 470-475.

Ehle, F. R. (1984). Influence of feed particle density on particulate passage from rumen of Holstein cow. Journal of Dairy Science 67, 693-697.

Faichney, G. J. (1975). The effect of formaldehyde treatment of a concentrate diet on the passage of solute and particle markers through the gastrointestinal tract of sheep. Australian Journal of Agricultural Research 13 , 319-327.

Fennessy, P. F., Greer, G. J. \& Forss, D. A. (1980). Voluntary intake and digestion in red deer and sheep. Proceedings of New Zealand Society of Animal Production 40, $158-162$.

Henke, S. E., Demaris, S. \& Pfister, J. A. (1988). Digestive capacity and diets of white-tailed deer and exotic ruminants. Journal of Wildlife Management 52, 595-598.

Hofmann, R. R. (1985). Digestive physiology of the deer-their morphophysiological specialization and adaptation. In Biology of Deer Production, pp. 393-407 [P. F. Fennessy and K. R. Drew, editors]. Wellington: The Royal Society of New Zealand.

Katoh, K., Sato, F., Yamazaki, A., Sasaki, Y. \& Tsuda, T. (1988). Passage of indigestible particles of various specific gravities in sheep and goats. British Journal of Nutrition 60, 683-687.

Kay, R. N. B. (1985). Seasonal variation of appetite in ruminants. In Recent Development in Animal Nutrition, pp. 199-210 [W. Haresign and D. J. A. Cole, editors]. London: Butterworths.

Kay, R. N. B. (1987). Comparative studies of food propulsion in ruminants. Physiological and Pharmacological Aspects of the Reticulo-rumen, pp. 155-170 [L. A. A. Ooms, A. D. Degryse and A. S. J. P. A. M. van Miert, editors]. Dordrecht: Martinus Nijhoff.

Kay, R. N. B. \& Goodall, E. D. (1976). The intake, digestibility and retention time of roughage diets by red deer (Cervus elaphus) and sheep. Proceedings of the Nutrition Society 35, $98 \mathrm{~A}-99 \mathrm{~A}$.

Lechner-Doll, M. \& Kaske, M. (1991). Factors affecting the retention time of particles in the forestomach of ruminants and camelids. In Phrsiological Aspects of Digestion and Metabolism in Ruminants [T. Tsuda. Y. Sasaki \& R. Kawashima, editors]. Orlando: Academic Press. 
Milne, J. A., Macrae, J. C., Spence, A. M. \& Wilson, S. (1978). A comparison of the voluntary intake and digestion of a range of forages at different times of the year by the sheep and the red deer. British Journal of Nutrition 40, 347-357.

Poppi, D. P., Norton, B. W., Minson, D. J. \& Hendricksen, R. E. (1980). The validity of the critical size theory for particles leaving the rumen. Journal of Agricultural Science, Cambridge 94, 275-280.

Takatsuki, S. (1989). Dwarf bamboo as forage for sika deer. In Proceedings, International Symposium on Deer Physiology and Production (Satellite Symposium of 7th International Symposium on Ruminant Physiology, Sendai, 1989), pp. 76-77. Ishinomaki, Japan: Japan Deer Farm Association.

Ulyatt, M. J., Dellow, D. W., John, A., Reid, C. S. W. \& Waghorn, G. C. (1986). Contribution of chewing during eating and rumination to the clearance of digesta from the ruminoreticulum. In Control of Digestion and Metabolism in Ruminants, pp. 498-515 [L. P. Milligan, W. L. Grovum and A. Dobson, editors]. Englewood Cliffs: Prentice-Hall.

Zar, J. H. (1984). Biostatistical Analysis, 2nd ed. [J. H. Zar, editor]. Englewood Cliffs: Prentice-Hall. 